\title{
Influence of Service Conditions of Quarry Dump Trucks on the Thermal State Large-size Tires
}

\author{
Kulpin Aleksandr G. ${ }^{\mathbf{1 , a}}$; Stenin Dmitriy V., ${ }^{\mathbf{1 , b}}$; Kultayev Evgeniy E. ${ }^{\mathbf{1 ,}}$; \\ Kulpina Evdokya E. ${ }^{1, d}$; Borovtsov Valeriy A., ${ }^{1, \mathrm{e}}$. \\ T. F. Gorbachev Kuzbass State Technical University, \\ Kemerovo, Russian Federation. \\ kag.ea@mail.rubstenindv@mail.ru cwow-wows@yandex.ru \\ ddanya707@list.ru dekanat.gemf@yandex.ru
}

\begin{abstract}
Operability of tires depends substantially on their thermal state. High operational temperature of tires worsens mechanical properties of tire materials and reduces their durability. The country average level of large-size and over large-size tires service life considerably decreases because of the tires which have failed as a result of thermal destructions. In order to decrease the operational temperature and, consequently, increase the service life of tires taking into account their hypersensibility to various service conditions, quality of production and other factors, complex researches of a thermal state have been made. Dependence of tire temperature on the load factor and speed was received. Such studies conducted to date are still insufficient. They have partial, local character and make it impossible to establish the regularities allowing to ensure the required performance of tires.
\end{abstract}

Keywords - dump truck for quarry; tire resource; temperature condition of tires; load factor.

\section{INTRODUCTION}

Open pit mining takes the leading place in the mining industry. In this method of production the main type of technical transport is the quarry motor transport. Costs of motor transport make $50-60 \%$ of prime cost of the transported mineral weight in which costs of fuel (more than 50\%) and tires (25-30\%) account for the most part [1][2] [3].

Currently, more efficient use of large-size tires resource is the reserve of decrease in cost of mineral transportation as shown in Figure 1[4].

Underutilisation of large-size tires resource happens for the following reasons:

- natural wear of a protector $(81 \%)$;

- thermal and fatigue failures which represent stratification of a cord, peeling of a protector and sidewalls (15\%);

- the mechanical damages caused by cuts and punctures of tires $(3 \%)$;

- production defect (1\%);

A number of factors influence the tires resource of dump truck for quarry, the basic of which are [5]:
- load factor;

- average operational speed of the movement, i.e. average speed of a dump truck for its time spent on the route. When calculating this speed, all the time of the car spent for getting the work order and the downtime during loading/unloading was considered;

- longitudinal inclination of the road;

- ambient temperature.

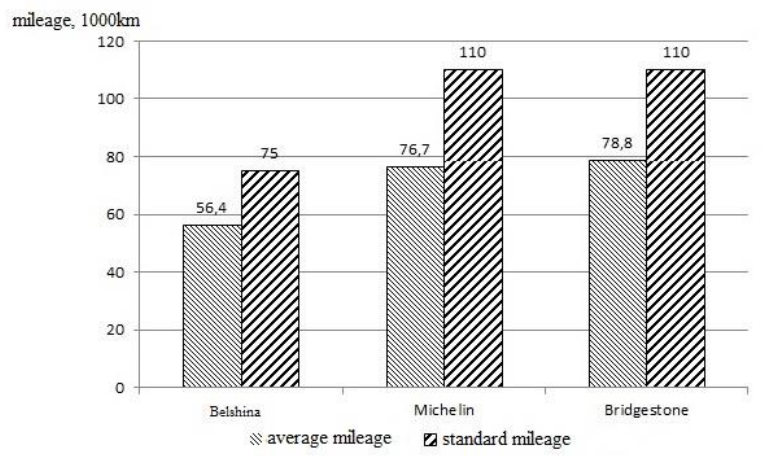

Fig. 1. Large-size tires operation

The above mentioned factors influence the thermal condition of the tire and hence its working capacity and the operation. At temperatures over $110{ }^{0} \mathrm{C}$ there is a deterioration in mechanical properties of the tire material that reduces its reliability, reduces wear resistance and durability.

It is impossible to affect all these factors as, for example, change of a longitudinal profile of the road is possible only at the stage of quarry formation, and it is impossible to influence ambient temperature in any way. Therefore, there are only two factors by means of which it is possible to manage tires operation: the average operational speed of a dump truck and its load factor.

The aims and the objectives of the study are as follows: increase of efficiency of quarry dump trucks by means of establishment and practical use of influence regularities of loading 
degree and travelling speed on the thermal condition of tires. For achievement of this purpose the following tasks have to be solved:

- Carry out pilot studies to determine the influence of a thermal condition of tires on productivity of quarry dump trucks;

- Develop models of tires temperature regression from the degree of loading, travelling speed, ambient temperature and the road longitudinal slope.

\section{MATERIALS AND METHODS}

For determination of rational values of average travelling speed and load factor the researches have been made experimentally in the conditions of branch of JSC "CC "of KQC "Kedrovsky Coal Mine". The object of the study at the same time was tires temperature condition of dump trucks the BelAZ - 75131, - 75136 with a loading capacity of $130 \mathrm{t}$. Researches were carried out by means of universal system of temperature monitoring which fixed tire temperature during the set time, and then the obtained information was processed on the personal computer.

Change of a temperature condition of tires was fixed by means of special sensors "termokhronDS1921GiButton". See the sensor in Figure 2.

TermokhronDS1921GiButton is a powerful, independent system which carries out measurements of temperature, also keeps results in the protected memory. Registration of temperature is made with a frequency established by the user in the form of absolute values and in the form of the histogram.

The sensors were installed on the rear right external wheel (Belshina, the model Bel-102, serial number 0509 Bel 1772, the size 33.00R51) and on the right forward wheel (MICHELIN, the model XDTA, serial number VVB074A2A, the size 33.00R51).
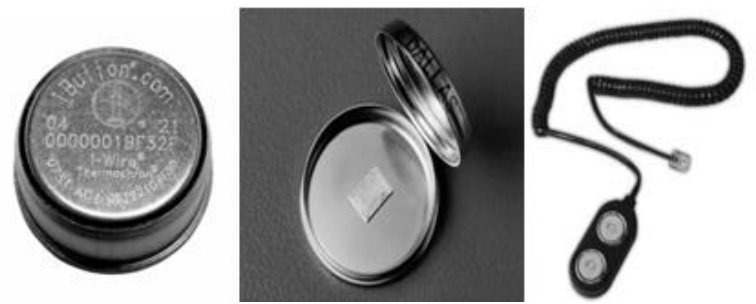

Fig. 2. Appearance of "TermokhronDS1921GiButton"

After dismantle of the wheels, the sensors have been fixed in the center of the racetrack and on the tire sidewall. The arrangement of the sensors in the wheel is shown in Figure 3.

For more convenient entering of data into the personal computer, such indications as ambient air temperature, road longitudinal inclination, and load factor were recorded by means of regular sensors of the remote parameter control system.
The experiment was conducted for 4 years, during all seasons of the year with the air temperature from $-43{ }^{0} \mathrm{C}$ to +38 ${ }^{0} \mathrm{C}$, the longitudinal inclination of the road varying from $0 \%$ to 9\%. More than 12000 measurements have been taken.

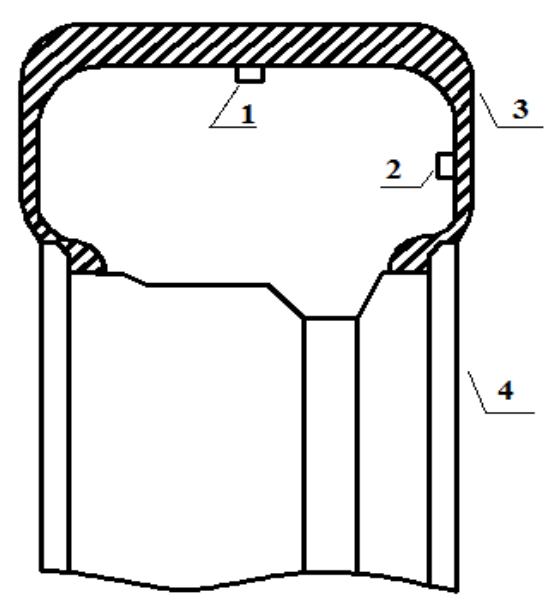

Fig. 3. Arrangement of sensors in a wheel 1 - the sensor located in the center of a racetrack; 2 - the sensor located on a tire sidewall; 3 - tire; 4 - wheel rim.

After the experiment was carried out, the data were processed, and the following equations of regression were received for the front and rear axles of the dump truck:

- Front axle:

$T_{t}=0,671 \cdot t_{a}+31,155 \cdot \gamma_{c}+0,812 \cdot v_{a . o . s}+0,073 \cdot i+32,976(1)$

- Rear axle:

$T_{t}=0,743 \cdot t_{a}+35,135 \cdot \gamma_{c}+1,547 \cdot v_{a . o . s}+6,541 \cdot i+27,992(2)$

where $T_{t}$ - temperature of tires;

$t_{a}$-air temperature;

$\gamma_{c}$ - load factor;

$V_{\text {a.o.s }}$ - average operational speed;

$i$ - longitudinal inclination of the road.

\section{RESULTS}

Processing of the experiment data has shown that temperature of tires changing from $+240 \mathrm{C}$ to $1050 \mathrm{C}$ depends on such parameters as the average operational speed of the dump truck movement and load factor. The average operational speed varied from 8 to $18 \mathrm{~km} / \mathrm{h}$, and the load factor - from 0.7 to 1.1 . Dependence of temperature of the tire (Тш) has the linear dependence presented in Figures 4 and 5. 


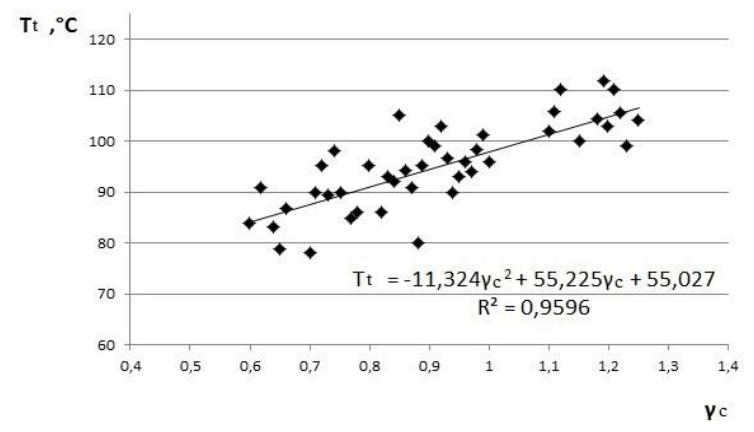

Fig. 4. Dependence of the tire temperature $T_{\mathrm{m}}$ on load factor $\gamma_{\text {гр }}$

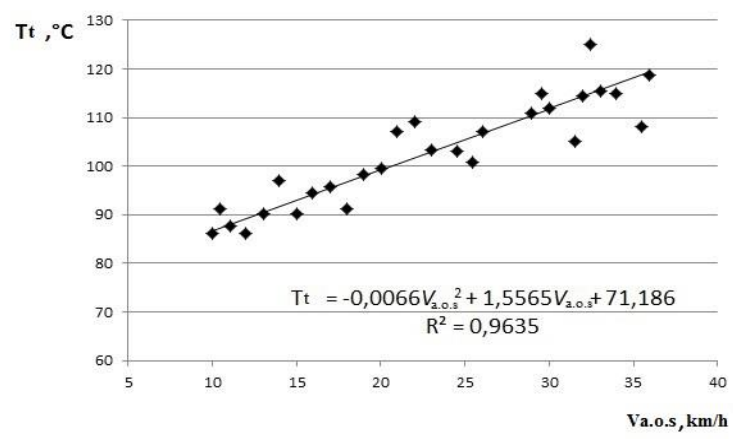

Fig. 5. Dependence of the tire temperature $T_{\amalg}$ on the speed of the dump truck movement $\mathrm{V}_{\mathrm{c}}$

\section{DISCUSSION}

As a measure of reliability of the equation of correlation dependence, the percentage of a mean square mistake of the equation to the average level of a productive indication $\left(\mathrm{y}^{-}=\mathrm{t}\right)$ is used:

$$
\sqrt{\frac{\sum(y-\hat{y}}{n-l}} \div \bar{y} \bullet 100 \%<15 \%
$$

where $\mathrm{y}$ - the actual value of a productive indication;

$\mathrm{y}^{\wedge}-$ value of a productive indication from the regression equation;

$$
\begin{aligned}
& \mathrm{n} \text { - number of measurements; } \\
& l \text {-number of parameters in the regression equation. }
\end{aligned}
$$

If this relation doesn't exceed $15 \%$, then it is necessary to consider that the regression equation rather well displays the studied interrelation.

For both groups of selection the percentage of a mean square mistake of the equation to the average level of a productive indication doesn't exceed $15 \%$ that speaks about reliability of the equation of correlation dependence. Therefore, for calculations it is possible to use these formulas which with a big reliability describe tires temperature condition of dump trucks.

TABLE 1. Percentage of a mean square mistake.

\begin{tabular}{|c|c|}
\hline Group of selection & $\begin{array}{c}\text { Percentage } \\
\text { ( }\end{array}$ \\
$\frac{\overline{\bar{y}}}{} \cdot 100 \%$ \\
\hline Front axle & $12,4 \%$ \\
\hline Rear axle & $14,2 \%$ \\
\hline
\end{tabular}

On the basis of these equations of regression, the computer program "Optimum degree of loading" (The certificate on the state registration of the computer program No. 2016613992) has been developed. By means of this program, it is possible to define optimum loading of a dump truck taking into account the thermal condition of tires in various service conditions.

\section{CONCLUSION}

The received dependences allow to define rational load factors that in turn will give the chance to use dump trucks more efficiently, i.e. to lower costs of their operation, to increase tires operation and to reduce cost of mining. It is established that for a dump truck BelAZ - 7531 a decrease in load factor to 0.7 leads to an increase in a life service of tires by $35-40 \%$ and a decrease in specific costs of tires by $3,5-4 \%$.

\section{REFERENCES}

[1] Influence of a longitudinal bias of the road on productivity of excavator and automobile complexes / A.A. Horeshok, A.S. Fuhrman//Messenger of KUZGTU. - 2015. - No. 3. - C. 19-22.

[2] Ashikhmin V. E., Fuhrman A.S., Shadrin V. N. Regularities of change of efficiency of excavator and automobile complexes from a longitudinal bias of the road. Vestnik Kuzb. gos. tekhn. univ. - 2012. - No. 4. - C. 120123.

[3] High-speed and operating modes of dump dump trucks / V. E. Ashikhmin, A.S. Fuhrman, V. N. Shadrin Vestnik Kuzb. gos. tekhn. univ. - 2012. - No. 4. - C. 123-125.

[4] Kulpin A.G., Stenin D.V., Kulpina E.E.Management of indicators of service conditions of large-size tires and their influence on productivity quarry avtosamosvalov. Collection of materials XV of the international scientific and practical conference "Natural and intellectual resources of Siberia. SIBRESURS 2014" - 2014

[5] Zenochkin M. Yu.Assessment of factors of wear and measure for increase of a resource of large-size tires quarry samosvalov. Mountain magazine. 2010. No. 1. - Page 86-88.

[6] Medveditskov S. I., Glebova N. M., Kormaz A.I. Programming of the parameters influencing productivity indicator for superlarge-size tires in the conditions of real operation. Mechanics of cars, mechanisms and materials. - 2015. - No. 2 (31).-Page 24-28.

[7] Adamov A. A., Tsvetkov R. V.The comparative analysis of the lower bound of temperature range of operability of three rubbers according to various Ispytaniy. Bulletin of the Perm national research polytechnical university. Mechanics. 2010. - No. 2. - From 5-16.

[8] Modelling and research of changes of structure of material at monoaxial stretching of the filled elastomer. / Morozov I. A.//Bulletin of the Perm national research polytechnical university. Mechanics. 2009. - No. 1. - C. 137-145.

[9] ADCAS SYSTEM of OFF-LINE ADAPTIVE CONTROL by the ACTIVE SUSPENSION BRACKET of the CAR. / Zhdanov A. A., Lipkevich D. B.//Works of Institute of system programming of the Russian Academy of Sciences No. 7.-2004. - Page 119-130.

[10] An assessment of efficiency of operation of large-size tires on coal mines of JSC HK SDS-UGOL. / Yefimov V. I., Krotikov O.V.//News of the Tula state university. Sciences about Earth. - 2013. - No. 2. - Page 112-117.

[11] Features of operation of a dump truck the BELAZ 75710 in the conditions of HK "SDS" of CHERNIGOVETS BRANCH OF JSC./Ivanov E.V.//In the collection: Russia young the Collection of materials VII of 
the All-Russian scientific and practical conference of young scientists with the international participation. - 2015. - Page 609

[12] The factors influencing change of pressure in car tires, and modern systems of his control. / Krasavin P. A., Fisichev G.V., Smirnov A.O., Kasimov N.O.//Magazine of automobile engineers. - 2015. - No. 3 (92). Page 16-21.

[13] A comparative assessment of dump dump trucks on Prime cost / Hodosevich A.N., Fuhrman A.S.//In the collection: Russia young the Collection of materials VII of the All-Russian scientific and practical conference of young scientists with the international participation. - 2015. - Page 612.

[14] Research of a thermal condition of tires quarry avtosamosvalov./Egorov A.A., Tuzovsky S. A., Kulpin A.G.//In the collection: Collection of reports of students, graduate students and faculty of university. By results of the IV All-Russian, 57th scientific and practical conference of young scientists "YOUNG RUSSIA" V. Yu. Blyumenstein (editor-in-chief).2012. - Page 169-172.

[15] Modelling of interaction of the wheel car with Soil / Barakhtanov L. V., Kotlyarenko V. I., Manyanin S. E., Sokolov I. A.//Magazine of automobile engineers, 2011, No. 2, p. $26-28$

[16] Barakhtanov L. V., Kotlyarenko V. I., Manyanin S. E., Sokolov I. A., Tumasov A. V. Modelling of the pneumowheel propeller of super and low pressure. settlement research of basic characteristics.//Magazine of automobile engineers, 2011, No. 1, p. 26 - 29
[17] Barakhtanov L. V., Kotlyarenko V. I., Manyanin S. E., Sokolov I. Development of final and element model of the tire. modelling of vertical, lateral, longitudinal nagruzheniy // Magazine of automobile engineers, 2012, No. 5 , p. 15 - 17

[18] Evzovich of B E, Raybmanp Car tires and wheels///Moscow: LLC MIROS, 2012, $159 \mathrm{p}$.

[19] Balabin I. V., Chabunin I. S., Putin V.A.Avtomobilnye and tractor wheels and tires // Moscow: MAMI, 2012, 919 p.

[20] / Goryunov S.V., Sharipov V. M.//Definition of operational loads of pneumatic tires quarry avtosamosvalovi International scientific and practical conference "Prospects of Development and Safety of a Motor Transportation Complex". - Novokuznetsk, 2011.

[21] Forecasting of operational temperature of pneumatic tires of dump dump trucks / Goryunov S.V., Sharipov V. M.//the Woods of Russia and economy 2013 in them. No. 1-2(42-43). Page 32-34.

[22] Research of dependence of temperature and internal pressure of air in the super and large-size tire from time of carrying out ispyta-ny/Medveditsk S. I., Kormaz A.I.//Magazine of automobile engineers. 2014. No. 5(88). Page 25-27. 